\title{
Reproducibility of wireless capsule endoscopy in the investigation of chronic obscure gastrointestinal bleeding
}

\author{
Dimitrios Christodoulou MD ${ }^{1,2}$, Gregory Haber MD FRCPC ${ }^{3}$, Umar Beejay MD ${ }^{4}$, Shou-jiang Tang MD ${ }^{1}$, \\ Simon Zanati $M D^{1}$, Rima Petroniene $\mathrm{MD}^{1}$, Maria Cirocco $M \mathrm{MC}^{1}$, Paul Kortan MD FRCPC ${ }^{1}$, \\ Gabor Kandel MD FRCPC ${ }^{1}$, Athina Tatsioni MD ${ }^{5}$, Epameinondas Tsianos MD², Norman Marcon MD FRCPC ${ }^{1}$
}

D Christodoulou, G Haber, U Beejay, et al. Reproducibility of wireless capsule endoscopy in the investigation of chronic obscure gastrointestinal bleeding. Can J Gastroenterol 2007;21(11):707-714.

BACKGROUND: Capsule endoscopy (CE) is a valuable tool in the diagnostic evaluation of obscure gastrointestinal bleeding, but limited information is available on the reproducibility of CE findings.

OBJECTIVE: To compare two successive CE studies with push enteroscopy $(\mathrm{PE})$ in patients presenting with chronic obscure gastrointestinal bleeding.

METHODS: A prospective study was conducted. Ten patients (seven men and three women) with chronic obscure gastrointestinal bleeding and no contraindications for CE were eligible and completed the trial. For each patient, the first capsule was administered on day 1 , the second capsule was administered on day 2 and PE was performed on day 3. Endoscopists were blinded to the capsule findings. Capsule findings were assessed independently by two investigators blinded to PE findings.

RESULTS: A potential small intestinal bleeding source was found in $60 \%$ of the patients when all the studies were combined. A bleeding source was found in four patients in both CE studies. The second CE also identified a bleeding source in a fifth patient. Interobserver agreement by kappa analysis was 0.642 to 1.000 $(\mathrm{P} \leq 0.05)$ for the CE studies. PE identified a potential small bowel bleeding site in four patients, including one patient who had negative CE studies.

CONCLUSIONS: This study confirmed the reproducibility of CE findings on successive studies. Some patients did not have a source of bleeding in the small intestine, and all studies found this.

Key Words: Capsule endoscopy; Obscure gastrointestinal bleeding; Push enteroscopy; Reproducibility

\section{La reproductibilité de l'endoscopie capsulaire sans fil dans l'exploration de saignements gastro-intestinaux occultes chroniques}

\begin{abstract}
HISTORIQUE : L'endoscopie capsulaire (EC) est un outil précieux pour l'évaluation diagnostique des saignements gastro-intestinaux occultes, mais on possède peu d'information sur la reproductibilité des résultats de l'EC.

OBJECTIF : Comparer deux études d'EC successives avec entéroscopie poussée (EP) chez des patients qui consultent en raison de saignements gastro-intestinaux occultes chroniques.

MÉTHODOLOGIE : Les auteurs ont procédé à une étude prospective. Dix patients (sept hommes et trois femmes) atteints de saignements gastro-intestinaux gastriques chroniques sans contre-indication d'EC y étaient admissibles et ont terminé l'étude. Pour chaque patient, la première capsule a été administrée le jour 1, la deuxième, le jour 2, puis l'EP a été exécutée le jour 3. Les endoscopistes n'étaient pas au courant des résultats des capsules, qui ont été évaluées de manière autonome par deux chercheurs non informés des résultats de l'EP.

RÉSULTATS : On a découvert une source potentielle des saignements du petit intestin chez $60 \%$ des patients une fois toutes les études combinées. On a découvert une source de saignement chez quatre patients dans les deux études d'EC. La deuxième EC a également permis de repérer une source de saignement chez un cinquième patient. La concordance entre observateurs par analyse kappa variait entre 0,642 et 1,000 ( $\mathrm{P} \leq 0,05)$ pour les études d'EC. L'EP a permis de repérer un foyer de saignement dans l'intestin grêle de quatre patients, y compris un patient dont les résultats aux études d'EC étaient négatifs.

CONCLUSIONS : La présente étude confirme la reproductibilité des résultats de l'EC dans des études successives. Certains patients n'avaient aucune source de saignement dans l'intestin grêle, et toutes les études l'ont décelé.
\end{abstract}

Chronic obscure gastrointestinal bleeding (COGB) is defined as bleeding of unknown origin that persists or recurs (ie, recurrent or persistent iron deficiency anemia, fecal occult blood testing positivity or visible bleeding) after a negative initial or primary endoscopic evaluation (colonoscopy and upper endoscopy) (1,2). The evaluation of COGB involves a series of increasingly interventional investigations such as repeat esophagogastroduodenoscopy and colonoscopy, push enteroscopy (PE) and small intestinal (SI) x-ray study (eg, enteroclysis), nuclear isotope bleeding scan, Meckel scan, angiography and intraoperative enteroscopy. Although PE can offer a diagnostic and therapeutic approach to the proximal small bowel, the patient undergoes an interventional procedure and the diagnostic yield is low.

The M2A video capsule, now marketed as PillCam (Given Imaging Ltd, Israel), is a diagnostic medical device

\footnotetext{
${ }^{1}$ The Centre for Therapeutic Endoscopy and Endoscopic Oncology, St Michael's Hospital, University of Toronto, Toronto, Ontario; ${ }^{2}$ Hepato-

Gastroenterology and Therapeutic Endoscopy Unit, 1st Division of Internal Medicine, Medical School of Ioannina, Ioannina, Greece; ${ }^{3}$ Division

of Gastroenterology, Lenox Hill Hospital, New York, New York, USA; ${ }^{4}$ The Royal London Hospital NHS Trust, Whitechapel, London,

United Kingdom; ${ }^{5}$ Department of Epidemiology, Medical School of Ioannina, Ioannina, Greece

Correspondence: Dr Dimitrios Christodoulou, 1st Division of Internal Medicine, Hepato-Gastroenterology and Therapeutic Endoscopy Unit,

Medical School of Ioannina, Greece, University Campus, Ioannina 45110, Ioannina, Greece. Telephone 30-265-109-9617,

fax 30-265-109-7883, e-mail dchristo@cc.uoi.gr

Received for publication August 14, 2006. Accepted January 29, 2007
} 


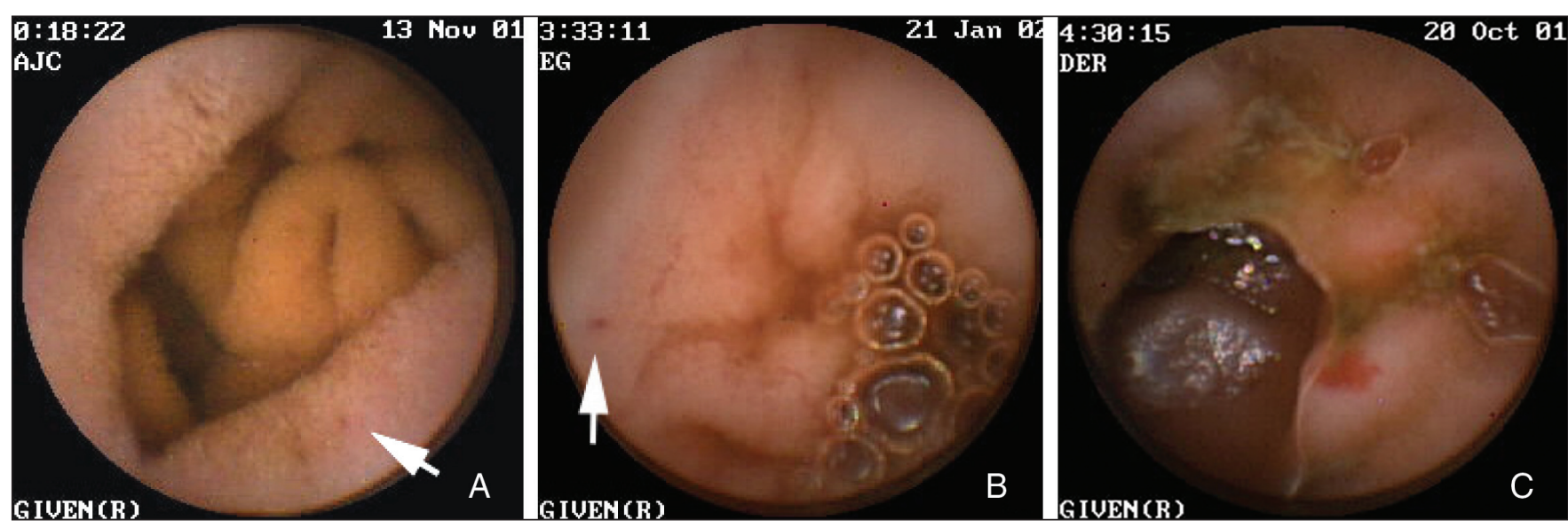

Figure 1) Endoscopic view of a tiny red spot (white arrow) (A), an indeterminate red lesion (white arrow) (B) and an angiodysplasia (C) as described in the study

that incorporates an ingestible wireless camera (3-8). There is increasingly more evidence reporting the utility of capsule endoscopy $(\mathrm{CE})$ in evaluating patients with COGB and other small bowel pathologies (9-11). However, there are no published data regarding the reproducibility of CE given consecutively to the same patient. The purpose of the present prospective study was to assess the reproducibility of CE given consecutively to the same COGB patient and to compare the findings with those of conventional PE in COGB patients.

\section{METHODS}

\section{Ethics}

The study protocol was approved by the research ethics board at St Michael's Hospital (Toronto, Ontario).

\section{Patients}

Patients 18 years of age or older with a history of COGB, who could give written informed consent, were eligible for the study. Exclusion criteria included known or suspected gastrointestinal (GI) obstruction, strictures or fistulas, the presence of cardiac pacemakers (although CE currently appears to be safe for patients with pacemakers, the test has not been approved for such patients) or other implanted electromedical devices, and a positive pregnancy test for women of child-bearing age. Demographic parameters included sex, age, race, weight and height. Related current and past medical history included prior surgery, comorbid conditions and medications. A standard physical examination was performed. Each patient was given two M2A capsules on two consecutive days and PE was performed on the third day.

\section{CE}

The patients fasted for $12 \mathrm{~h}$ before each capsule study. For improved bowel preparation, 2 L of GoLYTELY (Braintree Laboratories Inc, USA) were administered the previous day. Ease of swallowing the capsule was assessed using a visual analogue scale. $\mathrm{CE}$ was performed on day $1\left(\mathrm{CE}_{1}\right)$ with the Given M2A video capsule. On the following day, the patient returned for a second $\mathrm{CE}\left(\mathrm{CE}_{2}\right)$. The second M2A capsule was administered similarly.

The findings of CE were arbitrarily classified into definite, indeterminate and incidental. Definite findings included angiodysplasias (AVMs), tumours, fresh blood and melena (ie, changed blood). Indeterminate findings included nonbleeding red lesions and tiny red spots. Finally, incidental findings included phlebectasias, lymphangiectasias, small polyps and lymphoid nodules. AVMs were classified as red lesions larger than $1 \mathrm{~mm}$ in size, with a distinct border or spider-like projections and a bright red colour. Indeterminate red lesions included red lesions $1 \mathrm{~mm}$ to $3 \mathrm{~mm}$ in size without the asteroid configuration or bright red colour that is characteristic of AVMs. Finally, tiny red lesions were classified as pinpoint red lesions smaller than $1 \mathrm{~mm}$ in size (Figure 1).

The findings of the $\mathrm{CE}_{1}$ and $\mathrm{CE}_{2}$, as recorded by the first and second investigators, were divided into proximal, middle and distal according to the location of the lesion in the small bowel. The subjective estimation was based on the transit times, as defined by passage through the pyloric sphincter and the ileocecal valve. The localization software helped to identify the timeline of the capsule motion through the small bowel.

\section{PE}

On the third day of the present study, highly experienced endoscopists $(\mathrm{GH}, \mathrm{PK}, \mathrm{GK}, \mathrm{NM})$ performed PE on patients who were under conscious sedation, using a standard Olympus enteroscope PE1 (Olympus America Inc, USA) or an Olympus pediatric colonoscope PCF-160L (Olympus America Inc, USA). The enteroscope or the pediatric colonoscope was advanced as far as possible into the small bowel until the shaft of the instrument was fully inserted. Any lesion observed during insertion or withdrawal of the enteroscope or colonoscope was carefully documented in terms of its nature, location and size. For treatable bleeding lesions found during PE, appropriate endoscopic intervention was performed with argon plasma coagulation (APC).

Two investigators (UB and ST), both with previous experience in CE, reviewed all capsule images independently while blinded to PE findings and to each other's findings. Finally, two reviewers (GH and DC) coordinated the study, collected CE findings from both investigators, decided on a final diagnosis when there was a discrepancy in capsule interpretation by the two investigators and analyzed the data.

On day 4, the patients were asked to complete a questionnaire by using a visual analogue scale to assess pain or discomfort during the procedures. The patients were also asked 
TABLE 1

Results of the subjective assessment of capsule endoscopy (CE) and push enteroscopy (PE)

\begin{tabular}{lcc}
\hline Question & $\begin{array}{c}\text { CE rating, } \\
\text { mean }\end{array}$ & $\begin{array}{c}\text { PE rating, } \\
\text { mean }\end{array}$ \\
\hline $\begin{array}{l}\text { How would you rate the swallowing/ } \\
\text { insertion of the instrument? }\end{array}$ & 3.4 & 2.3 \\
$\begin{array}{l}\text { Did you experience pain during the } \\
\text { procedure? }\end{array}$ & 4.0 & 2.9 \\
$\quad \begin{array}{l}\text { Did you experience discomfort during the } \\
\text { procedure? }\end{array}$ & 3.8 & 2.4 \\
$\quad \begin{array}{l}\text { Did you experience pain after the } \\
\text { procedure? }\end{array}$ & 4.0 & 2.9 \\
$\quad \begin{array}{l}\text { Did you experience discomfort after the } \\
\text { procedure? }\end{array}$ & 4.0 & 2.9 \\
$\begin{array}{l}\text { How would you rate the procedure? } \\
\text { Rate the overall convenience of the test } \\
\text { If you were given the possibility to select } \\
\quad \text { an examination for diagnosing your } \\
\text { problem, would you choose this procedure?* }\end{array}$ & 3.7 & 2.6 \\
\hline
\end{tabular}

Ratings are based on the visual analogue scale, with a range of 0 to 4 , where

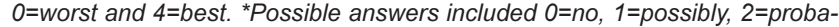
bly, 3=very probably and 4=yes

whether they would be willing to repeat $\mathrm{CE}$ or PE, if necessary (Table 1).

Statistical analysis in the present small study comprised individual data, frequency tables and descriptive statistics. A description of CE and PE findings, individual data and summaries were included in the analysis. Finally, a comparative analysis of the findings of $\mathrm{CE}_{1}, \mathrm{CE}_{2}$ and $\mathrm{PE}$ was made. The findings of the two investigators on the CE studies were compared by kappa analysis to assess the degree of agreement between the separate findings. In addition, the findings of $\mathrm{CE}_{1}$ and $\mathrm{CE}_{2}$ were also compared using kappa analysis to assess the degree of agreement. Statistical analysis and Cohen's kappa analysis were performed with the statistical package SPSS version 12 (SPSS Inc, USA). In kappa analysis, $\mathrm{k}=1$ implies perfect agreement and $\mathrm{k}=0$ suggests that the agreement is no better than what would be obtained by chance. There are no objective criteria for judging intermediate values in kappa analysis. However, kappa is often judged as providing poor agreement if $\mathrm{k} \leq 0.20$; fair agreement if $0.21 \leq \mathrm{k} \leq 0.40 ;$ moderate agreement if $0.41 \leq \mathrm{k} \leq 0.60$; substantial agreement if $0.61 \leq \mathrm{k} \leq 0.80$; and good agreement if $\mathrm{k}>0.80$.

\section{RESULTS}

Ten patients (seven men and three women) were enrolled in the study. The mean age of the study group was 74.2 years (range 64 to 86 years). The mean $( \pm \mathrm{SD})$ height of the patients was $167.5 \pm 10.6 \mathrm{~cm}$ (range $152.0 \mathrm{~cm}$ to $185.4 \mathrm{~cm}$ ) and the mean weight was $77.8 \pm 18.94 \mathrm{~kg}$ (range $54.6 \mathrm{~kg}$ to $113.0 \mathrm{~kg}$ ). The duration of COGB was $29.7 \pm 19.32$ months. The manifestations of COGB included intermittent melena or obvious blood loss in six patients, and iron deficiency anemia with positive fecal occult blood in four patients. The mean hemoglobin level was $96.6 \pm 18.4 \mathrm{~g} / \mathrm{L}$ (normal values: $125 \mathrm{~g} / \mathrm{L}$ to $185 \mathrm{~g} / \mathrm{L}$ ) and the mean ferritin level was $35.3 \pm 51.3 \mathrm{pmol} / \mathrm{L}$ (normal values: $30 \mathrm{pmol} / \mathrm{L}$ to $230 \mathrm{pmol} / \mathrm{L})$. A mean of $41.6 \pm 42.8$ units of blood was transfused, with a median of 17 units of blood

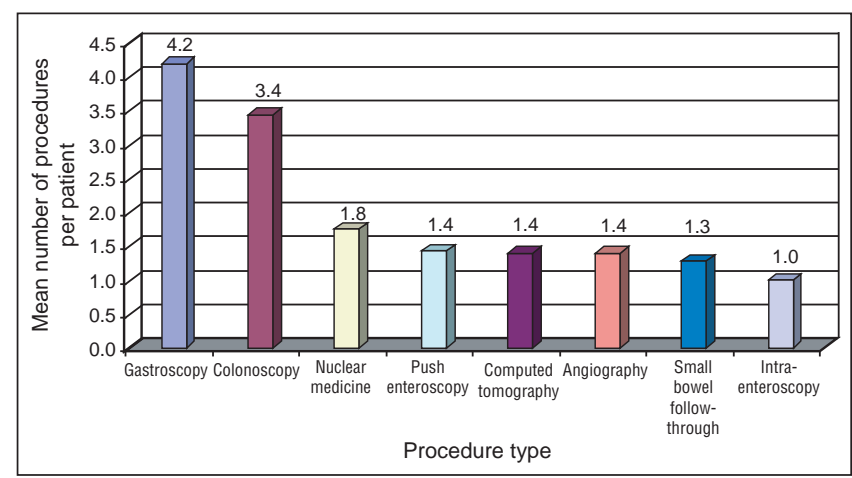

Figure 2) Mean number of previous procedures per patient before undergoing capsule endoscopy

(range, zero to 110 units of blood). The patients had been hospitalized a mean of $8.4 \pm 6.9$ times for the diagnostic investigation and treatment of their COGB. The mean number of previous procedures per patient before undergoing $\mathrm{CE}$ are shown in Figure 2.

Upper endoscopy showed that three of the 10 patients were treated for AVMs in the past. Colonoscopy showed diverticulosis in two patients and a cecal AVM that was treated in one patient. Previous PE showed jejunal AVMs in three patients. The lesions were treated by bipolar or APC but the chronic blood loss was continued. Small bowel followthrough showed a duodenal diverticulum in one patient. A nuclear scan showed positive findings in one patient without identifying the bleeding site, and angiography showed the suspected bleeding site in the small bowel in one patient. Two patients had also undergone intra-operative enteroscopy and in both of those cases, jejunal AVMs were seen and were treated by bipolar coagulation, but chronic bleeding continued.

All 10 patients completed the study. The M2A capsule was swallowed without any difficulty in all $20 \mathrm{CE}$ procedures. There were no complications and no patient complained of any symptoms during or after CE (Table 1). The capsule reached the cecum during the recording period in 17 of the $20 \mathrm{CE}$ procedures. Of the three cases in which the capsule did not reach the cecum during the recording period, in one case (patient 5, $\mathrm{CE}_{1}$ ), the capsule remained in the stomach for the whole recording time. In the other two cases, there was prolonged gastric retention of the capsule before crossing the pylorus. The mean small bowel transit time for $\mathrm{CE}_{1}$ was $3 \mathrm{~h} 49 \mathrm{~min} \pm 1 \mathrm{~h} 10 \mathrm{~min}$, and the mean small bowel transit time for $\mathrm{CE}_{2}$ was $3 \mathrm{~h} 28 \mathrm{~min}$ $\pm 1 \mathrm{~h} 7 \mathrm{~min}$. Likewise, PE was carried out successfully under conscious sedation in all patients, with no complications.

The findings of $\mathrm{CE}_{1}, \mathrm{CE}_{2}$ and $\mathrm{PE}$ are presented in Tables 2 and 3. The measurement of agreement between the two investigators and between the two CE procedures was calculated by using the kappa analysis, as described above (Table 4).

The comparison of the CE findings showed a good degree of agreement between the two investigators. Especially for the significant findings (Table 4), the range of kappa values was 0.642 to $1.000(\mathrm{P} \leq 0.05)$, showing a substantial to good degree of agreement between the two investigators. For the nonsignificant findings, the range of kappa values was 0.374 to 1.000 for the statistically significant comparisons that showed a moderate to good agreement between the investigators. Despite the overall good rate of agreement between the investigators, 
TABLE 2

Significant findings of the first capsule endoscopy $\left(C E_{1}\right)$, the second capsule endoscopy $\left(C E_{2}\right)$ and push enteroscopy in 10 patients, as determined by two investigators

\begin{tabular}{|c|c|c|c|c|c|c|c|c|c|c|}
\hline \multirow[b]{2}{*}{ Patient } & \multirow[b]{2}{*}{$\begin{array}{l}\operatorname{Age}^{*} I \\
\text { sex }\end{array}$} & \multirow[b]{2}{*}{$\begin{array}{l}\text { Presenting } \\
\text { symptom }\end{array}$} & \multirow[b]{2}{*}{$\begin{array}{l}\text { Hb/Ferritin, } \\
\text { (g/L)/(pmol/L) }\end{array}$} & \multirow[b]{2}{*}{$\begin{array}{c}\text { Transfused } \\
\text { units of blood }\end{array}$} & \multicolumn{2}{|l|}{$\mathrm{CE}_{1}$} & \multicolumn{2}{|c|}{$\mathrm{CE}_{2}$} & \multirow[b]{2}{*}{$\begin{array}{c}\text { Push } \\
\text { enteroscopy }\end{array}$} & \multirow[b]{2}{*}{ Comments } \\
\hline & & & & & $\begin{array}{c}\text { First } \\
\text { investigator ir }\end{array}$ & $\begin{array}{c}\text { Second } \\
\text { investigator }\end{array}$ & $\begin{array}{c}\text { First } \\
\text { investigator }\end{array}$ & $\begin{array}{c}\text { Second } \\
\text { investigator }\end{array}$ & & \\
\hline 1 & $68 / \mathrm{M}$ & Melena & $76 / 10$ & 110 & $\begin{array}{l}3 \text { AVM, } \\
\text { fresh blood }\end{array}$ & $\begin{array}{l}3 \text { AVM, } \\
\text { fresh blood }\end{array}$ & 2 AVM & 3 AVM & Negative & - \\
\hline 2 & $69 / M$ & Hematochezia & $95 / 165$ & 2 & Negative & Negative & Negative & Negative & Negative & $\begin{array}{l}\text { Bleeding from } \\
\text { stoma site }\end{array}$ \\
\hline 3 & $75 / F$ & $\begin{array}{l}\text { Melena and } \\
\text { hematochezia }\end{array}$ & ia $100 / 85$ & 14 & Negative & Negative & Negative & Negative & Negative & Diverticulosis \\
\hline 4 & $64 / \mathrm{M}$ & $\begin{array}{l}\text { Iron deficiency } \\
\text { anemia }\end{array}$ & $84 / 9$ & 0 & $\begin{array}{l}5 \mathrm{AVM}, \\
\text { melena }\end{array}$ & $\begin{array}{l}5 \text { AVM, } \\
\text { melena }\end{array}$ & $\begin{array}{l}6 \text { AVM, } \\
\text { fresh blood }\end{array}$ & $\begin{array}{l}6 \text { AVM, } \\
\text { fresh blood }\end{array}$ & d 3 AVM & - \\
\hline 5 & $82 / \mathrm{M}$ & Melena & $90 / 12$ & 12 & $\begin{array}{c}\text { Capsule stayed } \\
\text { in stomach }\end{array}$ & $\begin{array}{l}\text { d Capsule stayed } \\
\text { in stomach }\end{array}$ & d Negative & Negative & 1 AVM & - \\
\hline 6 & $86 / \mathrm{M}$ & $\begin{array}{l}\text { Iron deficiency } \\
\text { anemia }\end{array}$ & $76 / 3$ & 20 & $\begin{array}{l}\text { Tumour, } \\
\text { fresh blood }\end{array}$ & $\begin{array}{l}\text { Tumour, } \\
\text { fresh blood }\end{array}$ & Fresh blood & $\begin{array}{l}\text { Tumour, } \\
\text { fresh blood }\end{array}$ & d Negative & - \\
\hline 7 & $81 / F$ & $\begin{array}{l}\text { Iron deficiency } \\
\text { anemia }\end{array}$ & $110 / 27$ & 31 & Negative & Negative & 1 AVM & Negative & 3 AVM & - \\
\hline 8 & $73 / \mathrm{M}$ & Melena & $85 / 10$ & 93 & $\begin{array}{c}\text { Negative, } \\
2 \text { small } \\
\text { polyps }\end{array}$ & $\begin{array}{c}\text { Negative, } \\
1 \text { small } \\
\text { polyp }\end{array}$ & $\begin{array}{c}\text { Negative, } \\
1 \text { small } \\
\text { polyp }\end{array}$ & $\begin{array}{c}\text { Negative, } \\
2 \text { small } \\
\text { polyps }\end{array}$ & $\begin{array}{c}\text { Negative, } \\
1 \text { small } \\
\text { polyp }\end{array}$ & Myelodysplasia \\
\hline 9 & $75 / F$ & Melena & $120 / 10$ & 68 & 3 AVM & 4 AVM & 1 AVM & 1 AVM & 1 AVM & $\begin{array}{l}\text { Distal AVM not } \\
\text { seen in } \mathrm{CE}_{2} \\
\text { due to fluid }\end{array}$ \\
\hline 10 & $68 / M$ & $\begin{array}{l}\text { Iron deficiency } \\
\text { anemia }\end{array}$ & $130 / 22$ & 1 & Negative & Negative & Negative & Negative & $\begin{array}{l}\text { Cameron } \\
\text { lesions in } \\
\text { the fundus }\end{array}$ & $\begin{array}{l}\text { Bleeding site } \\
\text { not in the } \\
\text { small bowel }\end{array}$ \\
\hline
\end{tabular}

${ }^{*}$ Age is presented in years. AVM Angiodysplasia; F Female; Hb Hemoglobin; M Male

TABLE 3

Definite bleeding sources diagnosed by the various diagnostic procedures

\begin{tabular}{lclc}
\hline Procedure & $\begin{array}{c}\text { Positive findings, } \% \\
\text { (patients, } \mathbf{~} \text { ) }\end{array}$ & $\begin{array}{c}\text { Type of finding } \\
\text { (patients, } \mathbf{~} \text { ) }\end{array}$ & $\begin{array}{c}\text { Total lesions } \\
\text { found, } \mathbf{n}\end{array}$ \\
\hline $\mathrm{CE}_{1}$ & $40(4)$ & $\mathrm{AVM}(3)$, tumour (1) & 16 \\
$\mathrm{CE}_{2}$ & $50(5)$ & $\mathrm{AVM}(4)$, tumour (1) & 14 \\
$\mathrm{CE}_{1}+\mathrm{CE}_{2}$ & $50(5)$ & $\mathrm{AVM}(4)$, tumour (1) & 18 \\
$\mathrm{PE}$ & $40(4)$ & $\mathrm{AVM}(4)$ & 8 \\
$\mathrm{CE}_{1}+\mathrm{CE}_{2}+\mathrm{PE}$ & $60(6)$ & $\mathrm{AVM}(5)$, tumour (1) & 21
\end{tabular}

AVM Angiodysplasia; $C E_{1}$ First capsule endoscopy; $\mathrm{CE}_{2}$ Second capsule endoscopy; PE Push enteroscopy

one major significant finding (a tumour in patient 6) was missed by one investigator on $\mathrm{CE}_{2}$, while it was identified by both investigators on $\mathrm{CE}_{1}$ (Table 2 ).

The comparison of findings of the investigators showed a variable degree of agreement between $\mathrm{CE}_{1}$ and $\mathrm{CE}_{2}$. For the AVMs and tumour lesions, the degree of agreement between $\mathrm{CE}_{1}$ and $\mathrm{CE}_{2}$ was substantial to good $(\mathrm{k}=0.769$ to 1.000 , $\mathrm{P}<0.05)$. For the presence of fresh blood, the agreement between $\mathrm{CE}_{1}$ and $\mathrm{CE}_{2}$ was fair $(\mathrm{k}=0.357)$, likely because it may have been obvious that there was bleeding on one day but not obvious on another day. For the insignificant findings, the degree of agreement between $\mathrm{CE}_{1}$ and $\mathrm{CE}_{2}$ was moderate to $\operatorname{good}(k=0.500$ to 1.000$)$.

A potential SI bleeding source with the combination of all studies was found in $60 \%$ of patients $(n=6)$ (Table 3$). \mathrm{CE}_{1}$ found a bleeding source in four of the 10 patients. The lesions
TABLE 4

Kappa analysis (measure of agreement) for the significant and nonsignificant findings between the two investigators and between the first capsule endoscopy $\left(C_{1}\right)$ and the second capsule endoscopy $\left(\mathrm{CE}_{2}\right)$

\begin{tabular}{|c|c|c|c|c|c|c|}
\hline \multirow[b]{2}{*}{ Finding } & \multicolumn{3}{|c|}{$\begin{array}{c}\text { Investigator } 1 \text { versus } \\
\text { investigator } 2\end{array}$} & \multicolumn{3}{|c|}{$C E_{1}$ versus $C E_{2}$} \\
\hline & k & ASE & $\mathbf{P}$ & k & ASE & $\mathbf{P}$ \\
\hline AVMs* $^{*}$ & 0.883 & 0.113 & 0.000 & 0.769 & 0.212 & 0.018 \\
\hline Tumour* & 0.642 & 0.326 & 0.003 & 1 & 0.000 & 0.003 \\
\hline Fresh blood* & 1 & 0.000 & 0.000 & 0.357 & 0.367 & 0.284 \\
\hline Melena* & 1 & 0.000 & 0.000 & $\ddagger$ & $\ddagger$ & $\ddagger$ \\
\hline $\begin{array}{r}\text { Indeterminate } \\
\text { red lesions }{ }^{\dagger}\end{array}$ & 0.374 & 0.207 & 0.096 & 0.526 & 0.260 & 0.730 \\
\hline Tiny red spots ${ }^{\dagger}$ & 0.240 & 0.190 & 0.213 & 1 & 0.000 & 0.003 \\
\hline Phlebectasias $^{\dagger}$ & 0.578 & 0.203 & 0.005 & 0.500 & 0.306 & 0.134 \\
\hline Lymphangiectasias $^{\dagger}$ & 0.424 & 0.159 & 0.024 & 0.530 & 0.296 & 0.858 \\
\hline Small polyps ${ }^{\dagger}$ & 1 & 0.000 & 0.000 & 1 & 0.000 & 0.003 \\
\hline Lymphoid nodules $^{\dagger}$ & 1 & 0.000 & 0.000 & 1 & 0.000 & 0.003 \\
\hline
\end{tabular}

Agreement was poor if the kappa value $(k) \leq 0.20$; fair if $0.21 \leq k \leq 0.40$; moderate if $0.41 \leq k \leq 0.60$; substantial if $0.61 \leq k \leq 080$; and good if $k>0.80$. * Significant finding; ${ }^{\dagger}$ Nonsignificant finding; $¥$ No statistics were computed because $C E_{2}$ had a constant negative finding (no variance). ASE Asymptotic standard error; AVM Angiodysplasia

included AVMs, ranging in number from one to five in three of those four patients (Figures 3 to 5). Three of those four patients with positive findings had bleeding manifested by fresh blood $(n=2)$ or melena $(n=1)$. On $\mathrm{CE}_{1}$, one patient had an irregular area with fresh blood in the distal ileum, which 


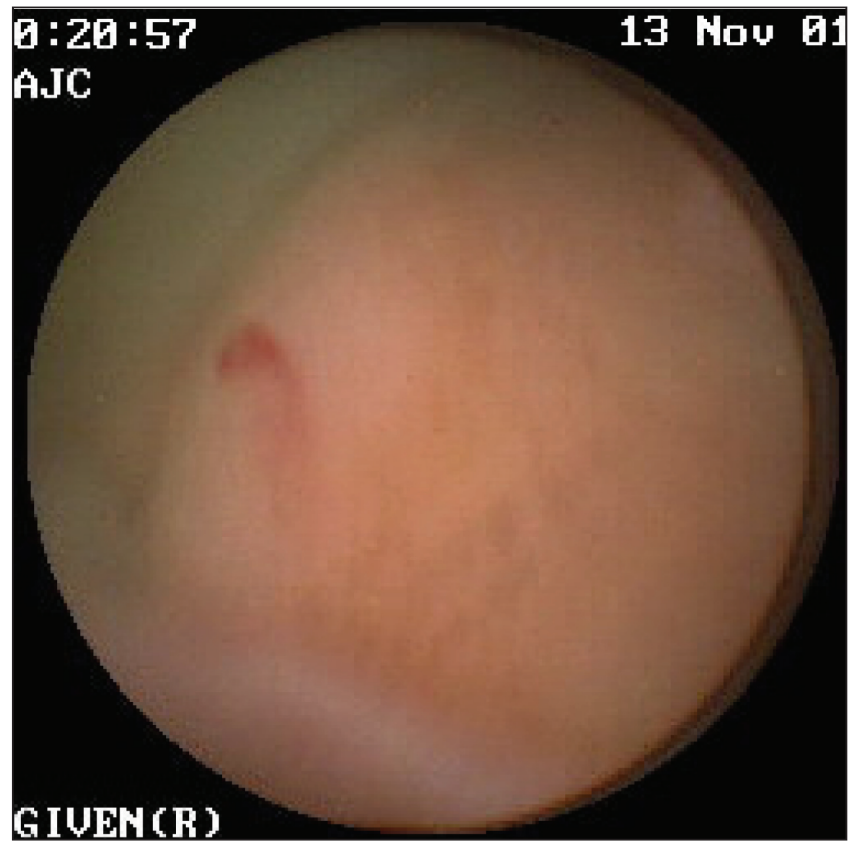

Figure 3) Endoscopic view of a bleeding angiodysplasia
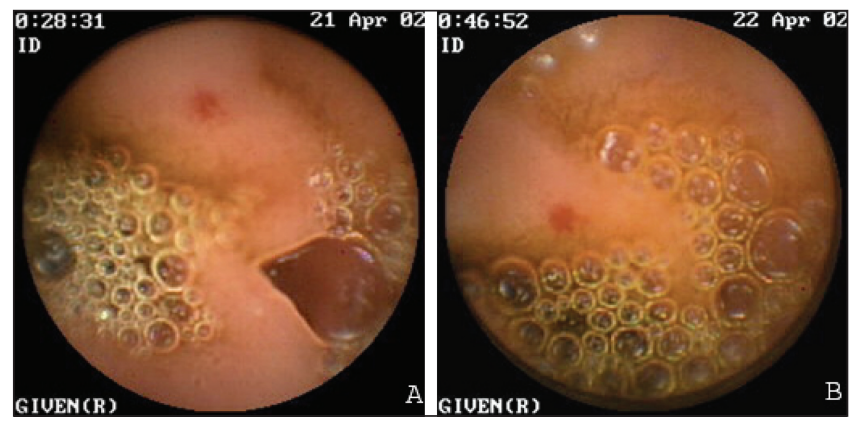

Figure 4) Endoscopic views of a small angiodysplasia identified on the first capsule endoscopy study (A) and on the second capsule endoscopy study (B). Both $\mathbf{A}$ and $\mathbf{B}$ are likely the same angiodysplasia

was diagnosed as a tumour (Figure 6). The patient underwent a computed tomography scan, which showed a focal irregular mass with thickening of the wall of the small bowel for approximately $5 \mathrm{~cm}$ to $6 \mathrm{~cm}$, with an irregular but patent lumen. There was no evidence of a small bowel obstruction proximal to the mass. There were also a few mildly prominent mesenteric nodes in the vicinity, which measured up to $9 \mathrm{~mm}$. Unfortunately, the patient died as the result of a heart attack before undergoing the operation.

In the other five patients, $\mathrm{CE}_{1}$ did not demonstrate a definite source of bleeding, but only some prominent submucosal veins, lymphangiectasias $(\mathrm{n}=4)$ and some small duodenal polyps $(n=1)$. In one patient, on $\mathrm{CE}_{1}$, the M2A capsule remained in the stomach for the whole duration of the test. Gastric findings included a few antral erosions, a gastric scar and mild erythema. Limited endoscopic views of the colonic mucosa were obtained in six patients, while two others had changed blood (ie, melena) and one other had a large amount of stool that did not allow any view of the colonic mucosa. $\mathrm{CE}_{2}$ gave results similar to those of $\mathrm{CE}_{1}$ (Figure 7). One of the investigators identified an AVM on one more patient (patient 7) on $\mathrm{CE}_{2}$ and this finding was confirmed by PE. In the

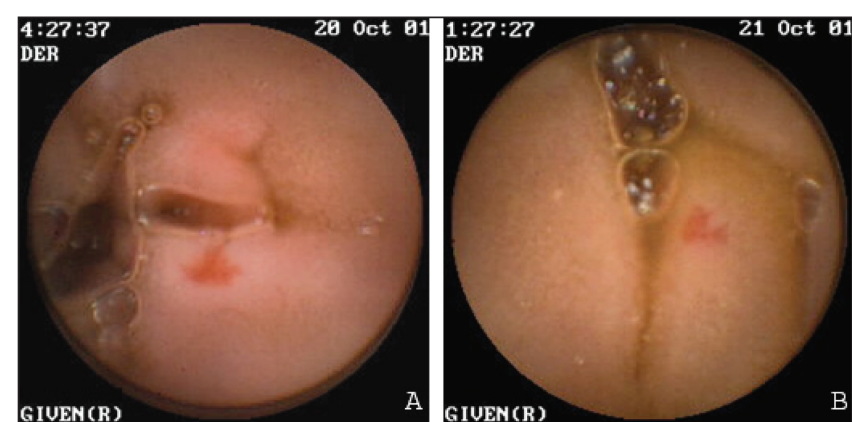

Figure 5) Endoscopic views of medium-size angiodysplasias identified on the first capsule endoscopy study (A) and on the second capsule endoscopy study (B)

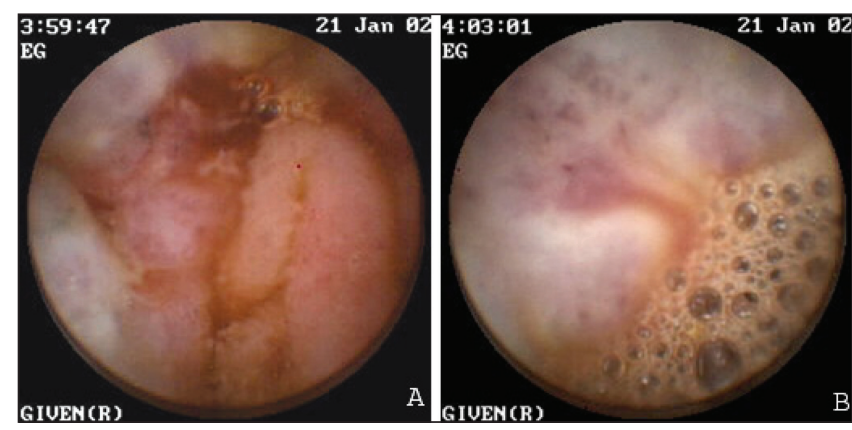

Figure 6) Endoscopic views of a bleeding tumour, as seen on the first capsule endoscopy study

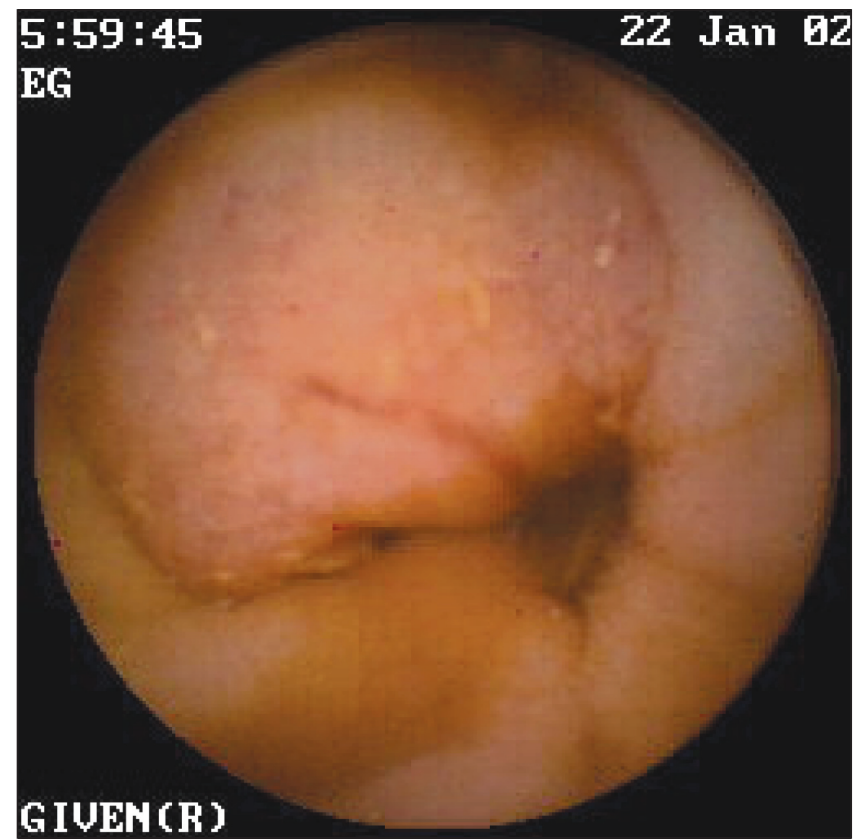

Figure 7) Endoscopic view of the bleeding tumour seen in Figure 6, as seen on the second capsule endoscopy study

diabetic patient (patient 5), the first capsule failed to get through the pylorus and the second capsule got through the pylorus $3 \mathrm{~h} 41 \mathrm{~min}$ after ingestion, but failed to demonstrate any bleeding sites.

\section{Therapy}

PE identified a potential small bowel bleeding site in four of the 10 patients. All four patients had AVMs. The first of 
them had three AVMs that were treated with APC, while the respective capsule studies had also shown AVMs on that patient. The second patient had one large jejunal AVM that was treated with APC, and that lesion was not identified by CE (however, the first capsule stayed in the stomach and in the second CE study, the view was limited because of fluid). The third patient had AVMs detected by PE (also found in one of the CE studies) and the fourth patient had a small AVM detected by PE (while AVMs were also identified by CE studies on that patient). Both of those patients received treatment with APC. In total, more significant findings were identified by CE $(n=18)$ than by PE $(n=8)$ (Table 3$)$.

Four patients had negative SI findings in both CE studies and PE examination. The first patient had diverticulosis and a history of cecal AVM, the second patient had chronic, intermittent blood loss from a stoma site, as proven by direct magnified inspection of the stoma during retrograde endoscopy, the third patient had Cameron gastric lesions and the fourth patient was found to have myelodysplastic syndrome as the cause of his chronic anemia.

The course of the disease was improved in the four patients who received APC treatment during PE for their AVMs. For the four patients with negative findings by $\mathrm{CE}$ and $\mathrm{PE}$, the exclusion of a small bowel disease led to improved management of their underlying GI disease or other disease. The patient with AVMs found by CE that were not found by PE (patient 1) underwent intraoperative enteroscopy with cauterization of some AVMs and the requirements for blood transfusions were reduced.

\section{DISCUSSION}

Evaluation of COGB is still one of the challenges in gastroenterology. It is estimated that in $5 \%$ to $10 \%$ of patients with COGB, the bleeding source cannot be identified by standard endoscopic techniques (ie, upper endoscopy and colonoscopy) $(1,2,12)$. For the diagnosis of COGB, it is suggested that a second upper endoscopy or "second opinion endoscopy" be performed, due to the high frequency of lesions that are overlooked at the initial endoscopy (1). Among these lesions are large hiatal hernias with Cameron lesions (underlying erosions or ulcers), peptic ulcer disease and vascular ectasia in the upper GI tract. Small bowel follow-through or enteroclysis, nuclear red blood cell scan and angiography can locate the bleeding site in only up to $10 \%$ to $20 \%$ of patients with COGB (13-15). PE, along with $\mathrm{CE}$, where available, is now the standard approach for the evaluation of COGB $(2,16,17)$. Intraoperative enteroscopy is usually performed when patients have transfusion-dependent bleeding from a source that cannot be located despite extensive diagnostic evaluation and when the risks of continued bleeding are judged to outweigh the risks of laparotomy. In general, the overall diagnostic yield of PE in identifying potential bleeding lesions in patients with COGB lies in the range of $38 \%$ to $75 \%$, whereas that of intraoperative enteroscopy ranges from $70 \%$ to $100 \%(2,13,14,16,18,19)$.

The present study showed that CE has good reproducibility and a satisfactory interobserver agreement rate. A second capsule, administered the next day, led to an identification of the same lesions as the first capsule for the great majority of lesions, with few exceptions. Good bowel preparation and passage of the capsule through the entire small bowel were the most important factors for identification of the same lesions by $\mathrm{CE}_{1}$ and $\mathrm{CE}_{2}$.
In an experimental study (3) that preceded human studies, CE was compared with PE in detecting small bowel lesions in an animal model that was developed specifically for this purpose. Overall, the CE sensitivity in detecting lesions randomly sewn in the full length of the small bowel was 64\% compared with $37 \%$ for PE. PE had a sensitivity of $94 \%$ in identifying beads within its range, compared with an overall sensitivity of 53\% for CE within the same range. In another short report (5), CE provided good views and successfully imaged small bowel pathological features in four patients with obscure or uncontrolled GI bleeding.

Some prospective trials $(9,10,20-27)$ compared CE with PE for the evaluation of COGB. Ell et al (10) included 32 patients in their study, and the diagnostic workup included small bowel enteroclysis, angiography, scintigraphy, PE and CE. Enteroclysis did not provide any diagnostic clue, while red blood cell scintigraphy was positive in one patient and celiac and mesenteric angiography was positive in four patients. PE provided relevant pathological findings in 38\% of the patients and identified a clear bleeding source in $28 \%(n=9)$ of the 32 patients. CE provided definitive evidence of a bleeding source in 21 of 32 patients $(66 \%)$, and the difference from PE was statistically significant. A study by Lewis and Swain (9) also compared CE with PE for the evaluation of suspected SI bleeding in 20 patients. The yield of PE in the evaluation of obscure bleeding was $30 \%(n=6)$ and the yield of CE was $55 \%$ $(n=11)$. The difference in yield between PE and CE did not reach significance. In another study (20), CE found a distal source of bleeding in five of 14 patients who had normal PE. In a study by Mylonaki et al (21), CE was more effective than PE in the evaluation of COGB (68\% versus $32 \%$ ) and led to an alteration in therapy in $66 \%$ of patients with positive findings. Other studies (22-26) confirmed those findings, but also showed that CE did not change the management of patients with indeterminate lesions, such as red spots or slight erythema, while it improved the clinical course in patients with significant findings such as angiectasias or focal ulcers. The studies described above showed that CE is an invaluable tool for the investigation of COGB. Other authors (27) stressed the efficacy of CE for the diagnosis of small bowel lesions because they found significant lesions in $62.9 \%$ of patients and identified the bleeding source in $75 \%$ of patients with iron deficiency anemia of obscure origin.

In a prospective study $(11,28)$ that compared CE with small bowel follow-through in 20 patients, CE was significantly more sensitive for the detection of small bowel diseases and of the potential SI bleeding source. Of interest, two case reports $(29,30)$ showed that CE identified a bleeding Meckel diverticulum after an extensive, nonconclusive diagnostic workup, including Meckel scintigraphy, in one of the two cases. It is clear that wireless CE is already a first-line tool for the investigation of small bowel diseases, but there is still more to investigate surrounding the fine details and findings of the procedure (24,31-34). From this perspective, the present study confirmed the high reproducibility rate of consecutive $\mathrm{CE}$ studies and used a clear terminology for the identified lesions.

Delvaux et al (25) studied 44 patients who underwent CE as the initial investigation of the small bowel when the gastroscopy and colonoscopy findings were normal. Further management decisions were based on CE results. After 12 months, follow-up data were obtained from all patients and referring physicians. CE detected an intestinal lesion in 18 patients 
(40.9\%). The findings were normal in 17 patients (38.6\%). CE detected upper GI lesions missed at gastroscopy in four patients and blood in the stomach in two patients or in the proximal colon in three patients, leading to new endoscopies. The positive predictive value of CE was $94.4 \%$ in patients with intestinal lesions, and the negative predictive value was $100 \%$ in patients with normal CE findings. CE significantly influenced the outcome after 12 months in $77.3 \%$ of patients - on the one hand, by detecting a bleeding source in the gut, and on the other, by ruling out an intestinal source of bleeding. Likewise, in an important multicentre study by Pennazio et al (35), the overall accuracy of CE was $91 \%$ and the subsequent management dictated by CE led to the resolution of the clinical problem in $65 \%$ of patients during a mean follow-up period of 18 months.

Another recent significant advance in small bowel endoscopy has been the introduction of a double-balloon enteroscopy system (Fujinon Corporation, Japan) (also named push-and-pull enteroscopy), a method that allows complete endoscopic examination of the small bowel in the ideal case, while tissue sampling and therapeutic interventions (such as thermal destruction, injection or polypectomy) can be performed during the same session $(18,36,37)$. In a recent study (38), the double-balloon system was used in patients with COGB (by the anterograde or retrograde approach, or both). The source of bleeding was identified in $76 \%$ of patients and complete small bowel enteroscopy was achieved in $86 \%$ of patients in whom the procedure was attempted (usually by a combination of the anterograde and retrograde approaches). This method also makes the treatment of many of the lesions that are identified by CE feasible, obviating the need for intraoperative enteroscopy and laparotomy $(39,40)$. It can also identify some of the lesions that are rarely missed by CE and the two methods can be considered complementary (41). Double-balloon enteroscopy can be used to insert the endoscope in parts of the small bowel that have altered anatomy as the result of surgical procedures (eg, the afferent limb of a Roux-en-Y anastomosis) (42). Finally, double-balloon enteroscopy has been an effective method for the extraction of entrapped CE capsules from the small bowel without the need for surgical laparotomy (43). Despite all the advantages of

\section{REFERENCES}

1. American Gastroenterological Association medical position statement: Evaluation and management of occult and obscure gastrointestinal bleeding. Gastroenterology 2000;118:197-201.

2. Waye JD. Small-intestinal endoscopy. Endoscopy 2001;33:24-30.

3. Appleyard M, Fireman Z, Glukhovsky A, et al. A randomized trial comparing wireless capsule endoscopy with push enteroscopy for the detection of small-bowel lesions. Gastroenterology 2000;119:1431-8.

4. Iddan G, Meron G, Glukhovsky A, Swain P. Wireless capsule endoscopy. Nature 2000;405:417.

5. Appleyard M, Glukhovsky A, Swain P. Wireless-capsule diagnostic endoscopy for recurrent small-bowel bleeding. N Engl J Med 2001;344:232-3.

6. Gong F, Swain P, Mills T. Wireless endoscopy. Gastrointest Endosc 2000;51:725-9.

7. Meron GD. The development of the swallowable video capsule (M2A). Gastrointest Endosc 2000;52:817-9.

8. Bradbury J. Journey to the centre of the body. Lancet 2000;356:2074.

9. Lewis BS, Swain P. Capsule endoscopy in the evaluation of patients with suspected small intestinal bleeding: Results of a pilot study. Gastrointest Endosc 2002;56:349-53. double-balloon enteroscopy, the technique also has some limitations: it is not widely available, it is very time consuming and has increased costs.

In the present study, both $\mathrm{CE}$ and $\mathrm{PE}$ were negative in four of the 10 patients, so in combination with the patients' relative history and relative findings, a bleeding source from the small bowel was excluded, as described above. For the six remaining patients with positive findings, CE identified one or more bleeding sources in five patients. The patient with a small bowel tumour had a regional transit abnormality of the M2A capsule at the area of the tumour, as was previously described by our group of researchers $(32,33)$. PE identified potential small bowel bleeding sources in four of the 10 patients. The most important finding of the present study was the high reproducibility of CE and the high degree of agreement between the investigators that reviewed the capsule videos, with few exceptions. In addition, $\mathrm{CE}$ was better tolerated by patients than was $\mathrm{PE}$, as was demonstrated by the subjective questionnaire completed by the patients (Table 1). No patient experienced pain or discomfort during $\mathrm{CE}$ and all patients rated the procedure very highly. The capsule was comfortable to swallow and the patients were willing to repeat the test, if necessary.

\section{CONCLUSIONS}

The present study provided further evidence regarding the value and reproducibility of $\mathrm{CE}$ during the evaluation of COGB. It is likely that CE, if available, should be the first test chosen for the investigation of suspected SI bleeding because it is easy, reliable and reproducible. In our opinion, PE should accompany $\mathrm{CE}$ for the complete investigation of the upper small bowel in patients with transfusion-dependent anemia and visible bleeding because it provides the option of therapeutic intervention. CE should be repeated if the capsule fails to reach the cecum during the recording period and in cases in which the view is limited due to the presence of fluid or food residue.

ACKNOWLEDGEMENTS: This study was sponsored by Given Imaging Ltd. Dr Christodoulou has received a scholarship/grant from the Greek Association of Gastroenterology for postgraduate training at St Michael's Hospital, Toronto, Ontario.
10. Ell C, Remke S, May A, Helou L, Henrich R, Mayer G. The first prospective controlled trial comparing wireless capsule endoscopy with push enteroscopy in chronic gastrointestinal bleeding. Endoscopy 2002;34:685-9.

11. Costamagna G, Shah SK, Riccioni ME, et al. A prospective trial comparing small bowel radiographs and video capsule endoscopy for suspected small bowel disease. Gastroenterology 2002;123:999-1005.

12. Swain P. Wireless capsule endoscopy. Gut 2003;52(Suppl 4):48-50.

13. Van Gossum A. Obscure digestive bleeding. Best Pract Res Clin Gastroenterol 2001;15:155-74.

14. Rossini FP, Pennazio M. Small-bowel endoscopy. Endoscopy 2002;34:13-20.

15. Melmed GY, Lo SK. Capsule endoscopy: Practical applications. Clin Gastroenterol Hepatol 2005;3:411-22.

16. Zuckerman GR, Prakash C, Askin MP, Lewis BS. AGA technical review on the evaluation and management of occult and obscure gastrointestinal bleeding. Gastroenterology 2000;118:201-21.

17. Tang SJ, Christodoulou D, Zanati S, et al. Wireless capsule endoscopy for obscure gastrointestinal bleeding: A single-centre, one-year experience. Can J Gastroenterol 2004;18:559-65.

18. Keuchel M, Hagenmuller F. Small bowel endoscopy. Endoscopy 2005;37:122-32. 
19. Eliakim R. Wireless capsule video endoscopy: Three years of experience. World J Gastroenterol 2004;10:1238-9.

20. Fleischer DE. Capsule endoscopy: The voyage is fantastic - will it change what we do? Gastrointest Endosc 2002;56:452-6.

21. Mylonaki M, Fritscher-Ravens A, Swain P. Wireless capsule endoscopy: A comparison with push enteroscopy in patients with gastroscopy and colonoscopy negative gastrointestinal bleeding. Gut 2003;52:1122-6.

22. Mata A, Bordas JM, Feu F, et al. Wireless capsule endoscopy in patients with obscure gastrointestinal bleeding: A comparative study with push enteroscopy. Aliment Pharmacol Ther 2004;20:189-94.

23. Adler DG, Knipschield M, Gostout C. A prospective comparison of capsule endoscopy and push enteroscopy in patients with GI bleeding of obscure origin. Gastrointest Endosc 2004;59:492-8.

24. Rastogi A, Schoen RE, Slivka A. Diagnostic yield and clinical outcomes of capsule endoscopy. Gastrointest Endosc 2004;60:959-64.

25. Delvaux M, Fassler I, Gay G. Clinical usefulness of endoscopic video capsule as the initial intestinal investigation in patients with obscure digestive bleeding: Validation of a diagnostic strategy based on the patient outcome after 12 months. Endoscopy 2004;36:1067-73

26. Pennazio M, Eisen G, Goldfarb N; ICCE. ICCE consensus for obscure gastrointestinal bleeding. Endoscopy 2005;37:1046-50

27. Scapa E, Jacob H, Lewkowicz S, et al. Initial experience of wirelesscapsule endoscopy for evaluating occult gastrointestinal bleeding and suspected small bowel pathology. Am J Gastroenterol 2002;97:2776-9.

28. Faigel DO, Fennerty MB. "Cutting the cord" for capsule endoscopy. Gastroenterology 2002;123:1385-8.

29. Mylonaki M, MacLean D, Fritscher-Ravens A, Swain P. Wireless capsule endoscopic detection of Meckel's diverticulum after nondiagnostic surgery. Endoscopy 2002;34:1018-20.

30. Tang SJ, Dubcenco E, Kortan P. Bleeding Meckel's diverticulum. Gastrointest Endosc 2004;60:264

31. Ginsberg GG, Barkun AN, Bosco JJ, et al. Wireless capsule endoscopy: August 2002. Gastrointest Endosc 2002;56:621-4.
32. Tang SJ, Zanati S, Dubcenco E, et al. Capsule endoscopy regional transit abnormality: A sign of underlying small bowel pathology. Gastrointest Endosc 2003;58:598-602.

33. Tang SJ, Haber GB. Capsule endoscopy in obscure gastrointestinal bleeding. Gastrointest Endosc Clin N Am 2004;14:87-100.

34. Tang SJ, Zanati S, Dubcenco E, et al. Diagnosis of small-bowel varices by capsule endoscopy. Gastrointest Endosc 2004;60:129-35.

35. Pennazio M, Santucci R, Rondonotti E, et al. Outcome of patients with obscure gastrointestinal bleeding after capsule endoscopy: Report of 100 consecutive cases. Gastroenterology 2004; 126:643-53.

36. May A, Nachbar L, Wardak A, Yamamoto H, Ell C. Doubleballoon enteroscopy: Preliminary experience in patients with obscure gastrointestinal bleeding or chronic abdominal pain. Endoscopy 2003;35:985-91.

37. Yamamoto H, Sekine Y, Sato Y, et al. Total enteroscopy with a nonsurgical steerable double-balloon method. Gastrointest Endosc 2001;53:216-20.

38. Yamamoto H, Kita H, Sunada K, et al. Clinical outcomes of double-balloon endoscopy for the diagnosis and treatment of smallintestinal diseases. Clin Gastroenterol Hepatol 2004;2:1010-6.

39. Ohmiva N, Taguchi A, Shirai K, et al. Endoscopic resection of Peutz-Jeghers polyps throughout the small intestine at doubleballoon enteroscopy without laparotomy. Gastrointest Endosc 2005;61:140-7.

40. Sunada K, Yamamoto H, Kita H, et al. Clinical outcomes of enteroscopy using the double-balloon method for strictures of the small intestine. World J Gastroenterol 2005;11:1087-9.

41. Gasbarrini A, Di Caro S, Mutignani M, et al. Double-balloon enteroscopy for diagnosis of a Meckel's diverticulum in a patient with GI bleeding of obscure origin. Gastrointest Endosc 2005;61:779-81.

42. Kuno A, Yamamoto H, Kita H, et al. Double-balloon enteroscopy through a Roux-en-Y anastomosis for EMR of an early carcinoma in the afferent duodenal limb. Gastrointest Endosc 2004;60:1032-4.

43. May A, Nachbar L, Ell C. Extraction of entrapped capsules from the small bowel by means of push-and-pull enteroscopy with the double-balloon technique. Endoscopy 2005;37:591-3. 


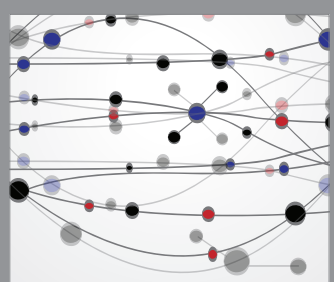

The Scientific World Journal
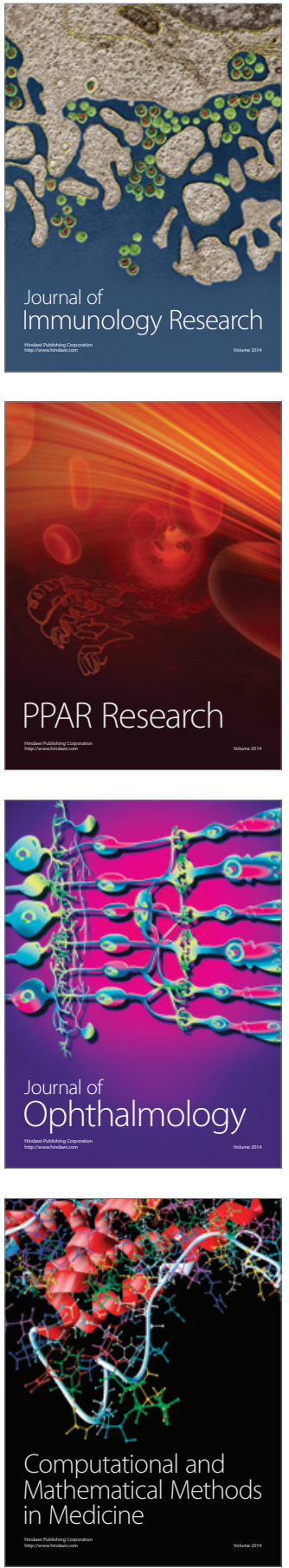

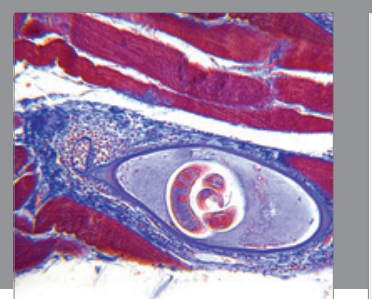

Gastroenterology Research and Practice

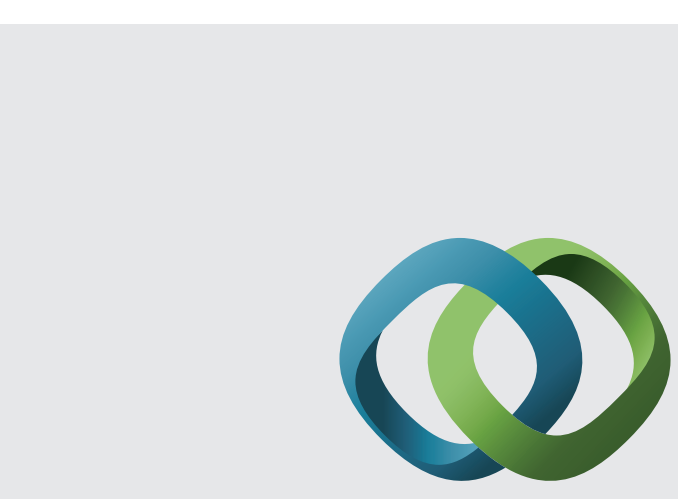

\section{Hindawi}

Submit your manuscripts at

http://www.hindawi.com
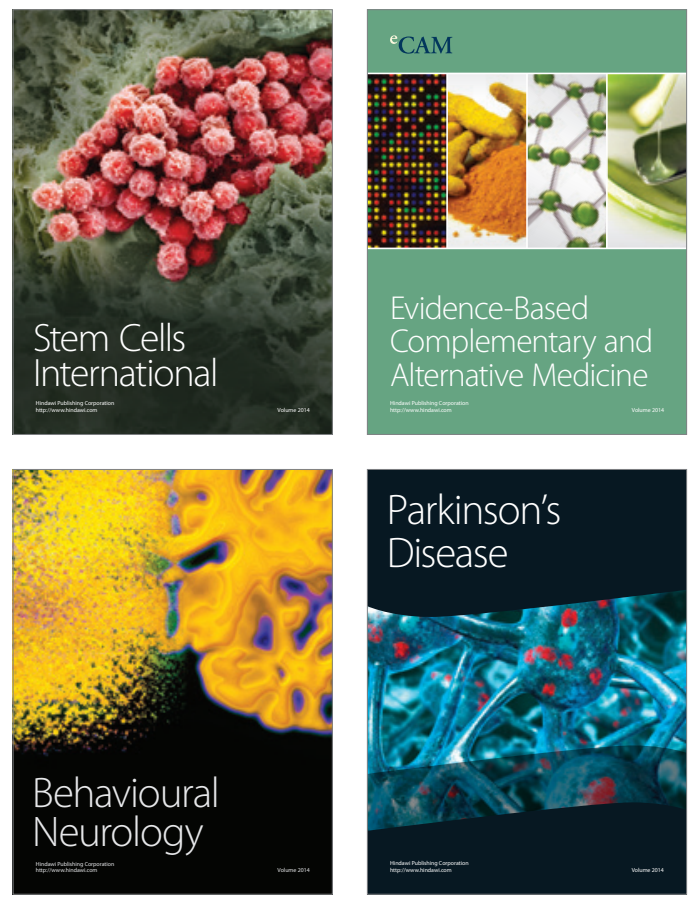
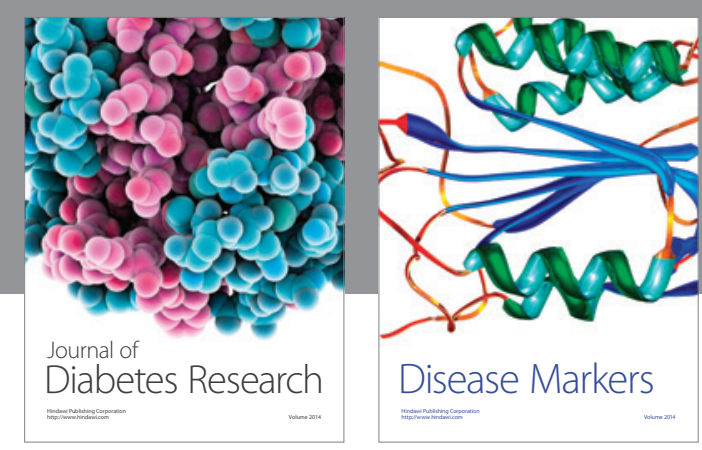

Disease Markers
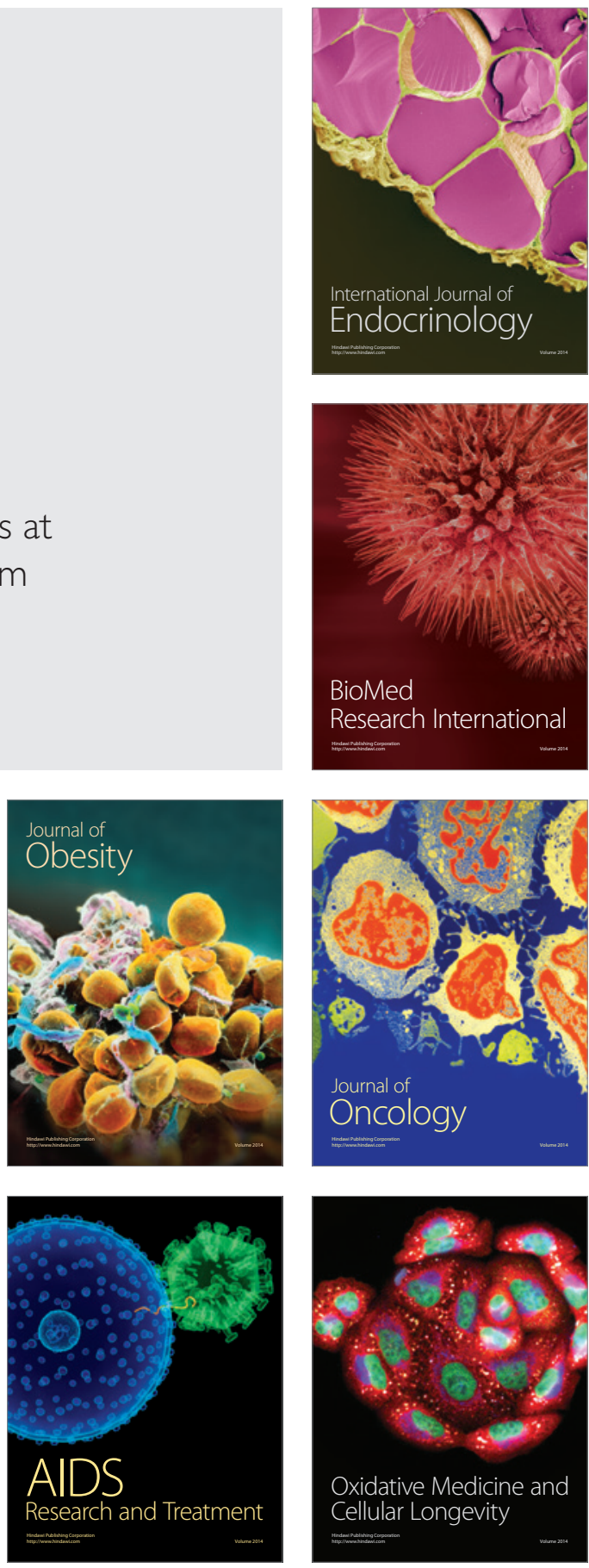